\title{
PLANTS
}

\section{VERDANT PRAIRIE IN 1999}

\author{
WENDY CALDWELL, Box 21, Ceylon, SK SOC 0T0
}

In over 50 years, I have never experienced wildflowers as prolific as they are this year, nor the grass so lush. With more than 11 inches of rain during the spring and summer, the pastures were a rich green until the end of July. In our little pasture behind our house, the grass grew so rank and tall that, for the first time in his 74 years on this farm, my husband, Wally, had to cut a swath around it so the cattle could see the fence!

The prairie has turned colour every week or two, a natural kaleidoscope: the mauve of crocuses, the white gardens of Moss Phlox; the yellow of buttercups and Golden Beans; the orange of Scarlet Mallow, Scarlet Gaura and Prairie Lilies.

My personal favourite is the gold season in all its shapes and sizes. I love a mixture of goldenrod and silver sage with a few Coneflowers to add contrast in colour and texture. It makes a bouquet fit for a queen.

Now, at the beginning of August, the purples are coming into full bloom: Meadow and Dotted Blazingstar with their fluffy spikes, and the turbans of the Purple Prairie-clover are turning the prairie magenta. Surely this is the season of royalty with magnificent gold, silver and purples. Along roadsides and fields are happy sunflower faces in no end of varieties: the large, brown-centered ones; tall, small ones in wet places, but still with brown centres; roadside ones with yellow centres.

The pungent odour of slough mint rises from the tractor wheels as haying season begins. The perfumes of cut hay and clover herald the beginning of harvest. Soon the air will be perfumed with the smells of ripening grain and combines.

How soon the seasons pass! Today (August 3) I picked a bouquet of Purple Prairie-clover, some Blazing-stars and a couple of varieties of sage. Water Smartweed

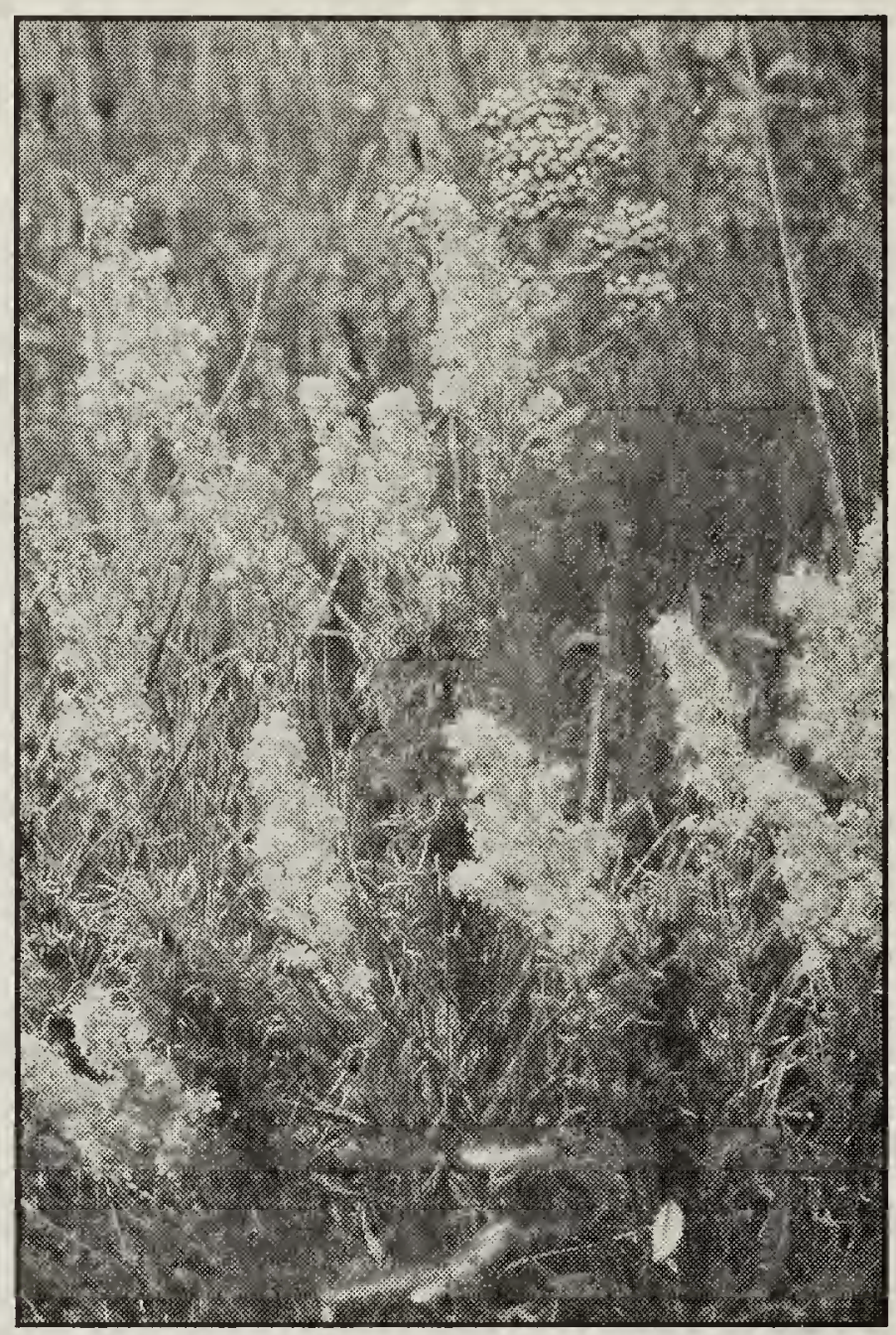

A bouquet of goldenrod and blazing star in August 1999 near Saskatoon.

Photo by Anna Leighton

that might have added a touch of pink, but I settled instead for a few Bachelor Buttons from my garden.

Will we ever experience such richness again? 